\section{Case Reports in Neurology}

Case Rep Neurol 2020;12:49-55

DOI: 10.1159/000507185

Published online: December 14, 2020
(C) 2020 The Author(s)

Published by S. Karger AG, Basel www.karger.com/crn

This article is licensed under the Creative Commons Attribution-NonCommercial 4.0 International License (CC BY-NC) (http://www.karger.com/Services/OpenAccessLicense). Usage and distribution for commercial purposes requires written permission.

\title{
Endovascular Recanalization in Early Recurrent Ischemic Stroke: A Treatment Challenge
}

\author{
Huong Bich Thi Nguyen ${ }^{a}$ Thang Huy Nguyen ${ }^{a, b}$ \\ ${ }^{a}$ Cerebrovascular Department, People's 115 Hospital, Ho Chi Minh City, Vietnam; bPham \\ Ngoc Thach University of Medicine, Ho Chi Minh City, Vietnam
}

\section{Keywords}

Early recurrent ischemic stroke $\cdot$ Thrombectomy $\cdot$ Reperfusion therapy $\cdot$ Stenting

\begin{abstract}
Reperfusion therapy is the most effective treatment for acute ischemic stroke. At present, many clinical studies have shown that mechanical thrombectomy is efficient and safe for acute ischemic stroke of large artery occlusion disease in the time window of $24 \mathrm{~h}$. However, there is limited information on the safety and effectiveness of this technique in cases of recurrent ischemic stroke. We report a case of early recurrent stroke of the anterior circulation after a week of the first stroke. Imaging examinations showed that there existed occlusion of corresponding vessels and obvious ischemic penumbra. Symptoms of the patient were progressive worsening and medical treatment failed; therefore, the corresponding vessel was opened. The low perfusion status in brain tissue and clinical defect symptoms of the patients have improved a lot. In conclusion, thrombectomy for early recurrent ischemic stroke may be effective. Moreover, there may be a wider reperfusion time window for ischemic stroke patients.
\end{abstract}




\section{Case Reports in Neurology}

Case Rep Neurol 2020;12:49-55

\begin{tabular}{l|l}
\hline DOI: 10.1159/000507185 & ๑ 2020 The Author(s). Published by S. Karger AG, Basel
\end{tabular} www.karger.com/crn

Nguyen and Nguyen: Endovascular Recanalization in Early Recurrent Ischemic Stroke

\section{Introduction}

Mechanical thrombectomy in combination with intravenous thrombolysis has become the gold standard treatment for acute ischemic stroke due to proximal large vessel occlusion of the anterior circulation [1]. In special clinical situations where intravenous thrombolysis is contraindicated, mechanical thrombectomy alone has also been found effective [2]. It is unclear whether patients can benefit from subsequent interventional recanalization of their occluded artery in recurrent ischemic stroke.

\section{Case Presentation}

A 50-year right-handed male was admitted to our department with mild right-sided hemiplegia, dysarthria $15 \mathrm{~h}$ after symptom onset. The National Institutes of Health Stroke Scale (NIHSS) score was 4. Medical history included hypertension and smoking. Acute non-contrast computed tomography (CT) showed left corona radiata infarction (Fig. 1a). Transcranial Doppler ultrasound revealed severe left middle cerebral artery (MCA) stenosis (Fig. 1b). Intravenous thrombolysis was contraindicated. He has been treated with dual platelet (aspirin plus clopidogrel) and statin and was discharged after 2 days with stable clinical condition.

On the next morning (day 7 after the index stroke), he was re-admitted with a wake-up stroke (last seen well $18 \mathrm{~h}$ before) and again had a right-sided hemiplegia and Broca's aphasia (NIHSS score: 18).

MRI revealed a new stroke and angiography showed left-sided MCA M1 occlusion (Fig. 2a). Perfusion imaging demonstrated an extensive diffusion-perfusion mismatch (132 mL). In the MRI perfusion parameters, the relative cerebral blood flow and relative cerebral blood volume are both still normal, whereas the time to maximum contrast $\left(\mathrm{T}_{\max }\right)$ and the mean transit time are significantly delayed over the left hemisphere indicating hypoperfusion (Fig. 2b-e, 3).

DSA revealed left M1 MCA occlusion (Fig. 4a). Mechanical thrombectomy and angioplasty were performed using a solitaire stent retriever (Fig. 4b). However, after the procedure, angiography on DSA still revealed severe stenosis at left M1 MCA (Fig. 4c). So, the patient underwent stenting for M1 MCA (Fig. 4d). After the procedure, the patient showed rapid major neurological improvement. NIHSS score $24 \mathrm{~h}$ after thrombectomy was 5 . There were no parenchymal hemorrhages noted after the procedure and he was discharged 3 days later.

\section{Discussion}

We present a case in which endovascular recanalization could be performed in a patient with intra-artery occlusion during the second stroke when small infarctions were present but there were larger areas of low perfusion. The procedure improved neurological function and reduced the incidence of disability even when the procedure was done several days later.

Presently, recanalization outside the time windows with bridging therapy is without clinical evidence and risk of hemorrhage or worsening of stroke from hyperperfusion syndrome is high [1]. The ischemic penumbra around the infarct tissue may be preserved if blood flow is restored. However, if blood flow is not restored for a long time, brain cells would not survive, which would lead to a worsening of clinical symptoms and even death. The risk of hemorrhage

\section{Karger'=}




\section{Case Reports in Neurology}

Case Rep Neurol 2020;12:49-55

DOI: 10.1159/000507185

Nguyen and Nguyen: Endovascular Recanalization in Early Recurrent Ischemic Stroke

(c) 2020 The Author(s). Published by S. Karger AG, Basel www.karger.com/crn

after reperfusion may depend on the size of the infarction. Therefore, we suggest that it is still feasible to recanalize when the volume of cerebral infarction is small and the area of low perfusion is large, even if the presence of cerebral infarction has been prolonged. This could be the theoretical basis for a possible successful recanalization of an occluded large artery in recurrent ischemic stroke.

Symptomatic intracranial stenosis carried a high risk of recurrent stroke within the first year, particularly in Asian and black patients [3]. To date, medical management, including antiplatelet therapy, intensive cardiovascular risk factor control, as well as lifestyle management, is still recommended as the first-line therapy for symptomatic intracranial artery stenosis to prevent recurrent transient ischemic attack and ischemic stroke. However, despite intensive medical management, a high risk of recurrent TIA and stroke was still observed in patients with high-grade (70-99\%) symptomatic intracranial artery stenosis.

Although the results of both the SAMMPRIS and VISSIT (the Vitesse Intracranial Stent Study for Ischemic Stroke Therapy) trials supported the use of aggressive medical management as being superior to stent therapy $[4,5]$, endovascular treatment of symptomatic ICAS has been facing controversy since the publication of the SAMMPRIS trial. Wingspan stent, the only type of stent used in SAMMPRIS, was approved and recommended for use by the Food and Drug Administration only in symptomatic patients who have had $\geq 2$ strokes despite aggressive medical management and have $70-99 \%$ stenosis because of atherosclerosis of the intracranial artery related to the recurrent strokes [6]. Patients who failed antithrombotic therapy may benefit more from endovascular treatment than those who did not. In the SAMMPRIS trial, 16 patients (7.0\%) in the stenting group had a disabling or fatal stroke within 30 days, mostly due to periprocedural complications as compared with 4 patients $(1.8 \%)$ in the medical group. Interestingly, the SAMMPRIS trial results demonstrated that the rate of death and disabling stroke beyond 30 days was lower in the stenting group at $2.2 \%$ than the medical therapy group at $6.2 \%$, so the worse clinical results for stenting in the SAMMPRIS trial were because of the high periprocedural morbidity and not delayed events. A study that included symptomatic ICAS patients, with 95.5\% (43/45) failing at least one kind of antithrombotic therapy, showed a 30-day stroke or vascular death rate of $6.6 \%$ after endovascular treatment, which was significantly better than SAMMPRIS $(14.7 \%)[4,7]$.

Recently, the results of the Chinese Angioplasty and Stenting for Symptomatic Intracranial Severe Stenosis trial and the Wingspan Stent System Post Market Surveillance Study (WEAVE trial) [8] showed 2-2.7\% periprocedural complications. This result provides promise as another treatment option for those patients who fail medical therapy for high-grade intracranial atherosclerotic stenosis. It is time to evaluate the role of intracranial stenting for the prevention of disabling or fatal stroke. In this case, we performed stenting after failing with aggressive medical treatment.

The study results of an additional Wingspan trial are pending: the CASSISS trial (China Angioplasty and Stenting for Symptomatic Intracranial Severe Stenosis) from China. This trial has demonstrated similar safety results with the on-label use of the stent in early reports and will likely give additional supporting data for the safe use of self-expanding stents.

In conclusion, mechanical thrombectomy for early recurrent ischemic stroke may be effective. Moreover, there may be a wider reperfusion time window for ischemic stroke patients. Patients with intracranial cerebral artery stenosis, who failed medical treatment, may benefit from stenting.

\section{Karger'=}




\section{Case Reports in Neurology}

\section{Acknowledgement}

Dr. Vu Thanh Tran, Dr. Tri Quang Nguyen, and Dr. Tan Cong Doan interpreted the images, treated the patient, and provided patient data.

\section{Statement of Ethics}

Written informed consent was obtained from the patient for publication of this case report and any accompanying images.

\section{Conflict of Interest Statement}

The authors have no conflicts of interest to declare.

\section{Funding Sources}

The author received no financial support for the research, authorship, and publication of this article.

\section{Author Contributions}

Huong B.T. Nguyen was a major contributor in writing the manuscript and performing the literature review. Thang H. Nguyen interpreted the patient data and was a major contributor in writing the manuscript. All authors read and approved the final manuscript.

\section{References}

1 Badhiwala JH, Nassiri F, Alhazzani W, Selim MH, Farrokhyar F, Spears J, et al. Endovascular thrombectomy for acute ischemic stroke: a meta-analysis. JAMA. 2015 Nov;314(17):1832-43.

2 Alonso de Leciñana M, Martínez-Sánchez P, García-Pastor A, Kawiorski MM, Calleja P, Sanz-Cuesta BE, et al. Mechanical thrombectomy in patients with medical contraindications for intravenous thrombolysis: a prospective observational study. J Neurointerv Surg. 2017 Nov;9(11):1041-6.

3 Miao ZR, Feng L, Li S, Zhu F, Ji X, Jiao L, et al. Treatment of symptomatic middle cerebral artery stenosis with balloon-mounted stents: long-term follow-up at a single center. Neurosurgery. 2009 Jan;64(1):79-84.

4 Chimowitz MI, Lynn MJ, Derdeyn CP, Turan TN, Fiorella D, Lane BF, et al.; SAMMPRIS Trial Investigators. Stenting versus aggressive medical therapy for intracranial arterial stenosis. N Engl J Med. 2011 Sep;365(11):993-1003.

5 Zaidat OO, Fitzsimmons BF, Woodward BK, Wang Z, Killer-Oberpfalzer M, Wakhloo A, et al. Effect of a balloon-expandable intracranial stent vs medical therapy on risk of stroke in patients with symptomatic intracranial stenosis: the Vitesse Intracranial Stent Study for Ischemic Stroke Therapy randomized clinical trial. JAMA. 2015;313(12):1240-8.

6 Bose A, Hartmann M, Henkes H, Liu HM, Teng MM, Szikora I, et al. A novel, self-expanding, nitinol stent in medically refractory intracranial atherosclerotic stenoses: the Wingspan study. Stroke. 2007 May;38(5):1531-7.

7 Samaniego EA, Tari-Capone F, Linfante I, Silva CF, Spilberg G, Gounis M, et al. Wingspan experience in the treatment of symptomatic intracranial atherosclerotic disease after antithrombotic failure. J Neurointerv Surg. 2013 Jul;5(4):302-5.

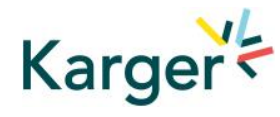


Case Reports in Neurology
Case Rep Neurol 2020;12:49-55

DOI: 10.1159/000507185

(c) 2020 The Author(s). Published by S. Karger AG, Basel www.karger.com/crn

Nguyen and Nguyen: Endovascular Recanalization in Early Recurrent Ischemic Stroke

8 Alexander MJ, Chaloupka JC, Zauner A, Baxter B, Callison RC, Gupta R, et al. The Wingspan Stent System Post Market Surveillance trial: final trial results in 150 patients treated on-label. Los Angeles, CA: International Stroke Conference, 2018.

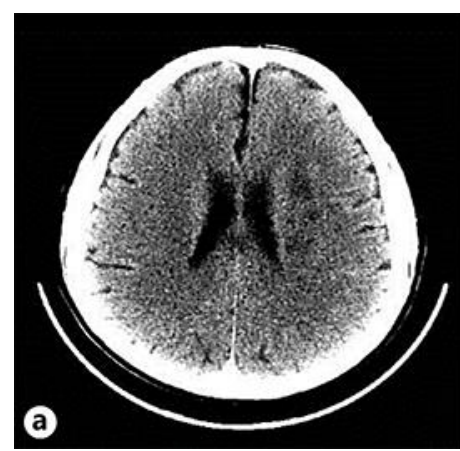

LMCA

12:46:57 PM

Depth

Power 100

Sample 6

Peak 269*

Dias $99^{*}$

Mean $167^{*}$

P.I. $1.02^{*}$

(a)

b

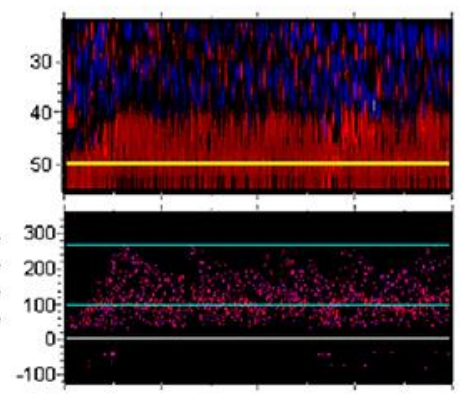

Fig. 1. First non-contrast CT showed left corona radiata infarction (a); TCD revealed severe stenosis on left M1 MCA with mean flow velocity $>100 \mathrm{~cm} / \mathrm{s}$ (b). 
Case Reports in Neurology

\begin{tabular}{l|l}
\hline Case Rep Neurol 2020;12:49-55 \\
\hline DOI: 10.1159/000507185 & $\begin{array}{l}\text { @ 2020 The Author(s). Published by S. Karger AG, Basel } \\
\text { www.karger.com/crn }\end{array}$ \\
\hline
\end{tabular}

Nguyen and Nguyen: Endovascular Recanalization in Early Recurrent Ischemic Stroke
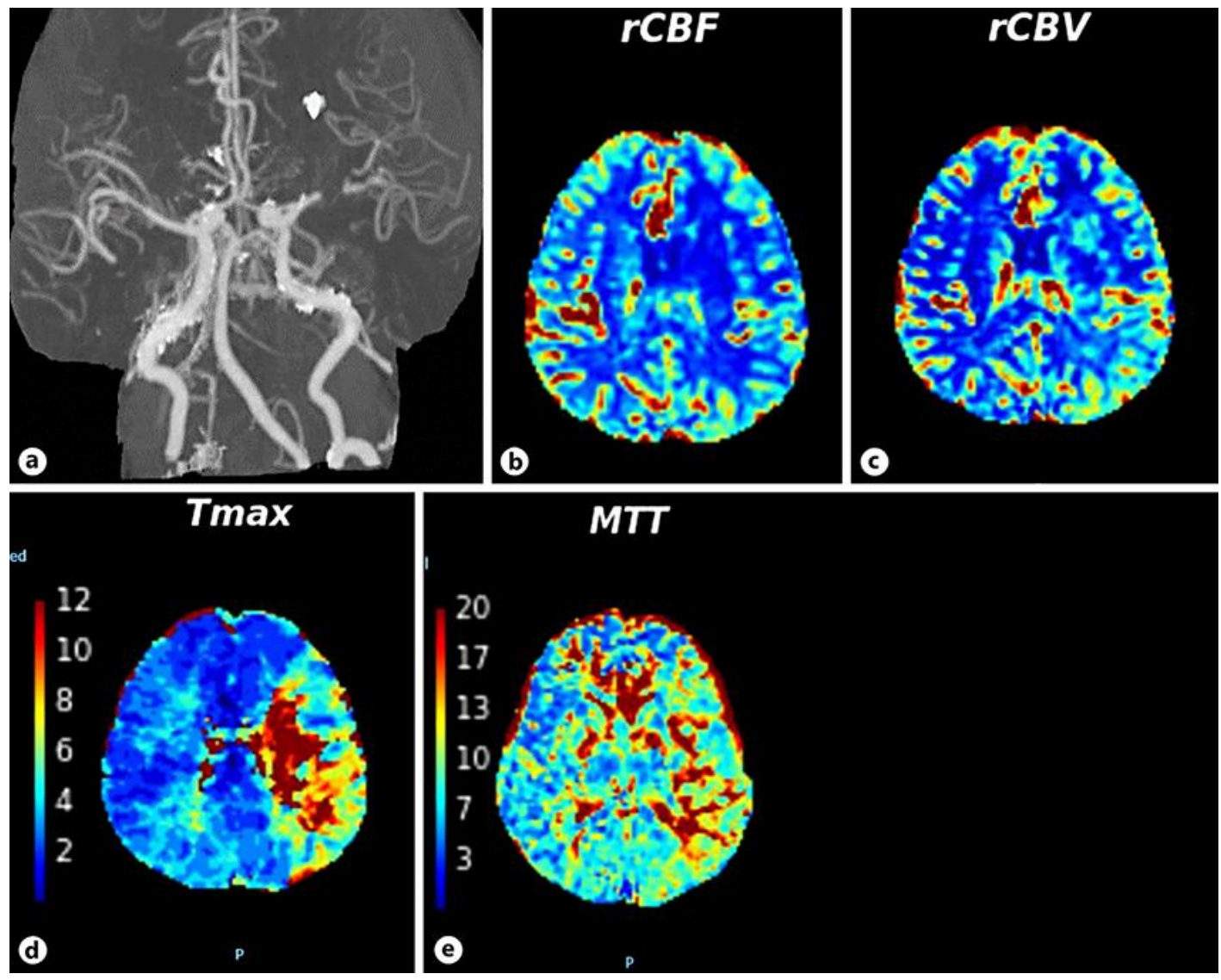

Fig. 2. CT angiography after 1 week revealed left M1 MCA occlusion (a). b-e The perfusion parameters: relative cerebral blood flow ( $\mathrm{rCBF}$ ) and relative cerebral blood volume (rCBV) that are both still normal, whereas the time to maximum contrast ( $\mathrm{T}_{\max }$ ) and the mean transit time (MTT) are significantly delayed over the left hemisphere indicating hypoperfusion. This imaging showed an extensive diffusion-perfusion mismatch $(132 \mathrm{~mL})$. 
Case Reports in Neurology

\begin{tabular}{l|l}
\hline Case Rep Neurol 2020;12:49-55 \\
\hline DOI: 10.1159/000507185 & $\begin{array}{l}\text { @ 2020 The Author(s). Published by S. Karger AG, Basel } \\
\text { www.karger.com/crn }\end{array}$ \\
\hline
\end{tabular}

Nguyen and Nguyen: Endovascular Recanalization in Early Recurrent Ischemic Stroke

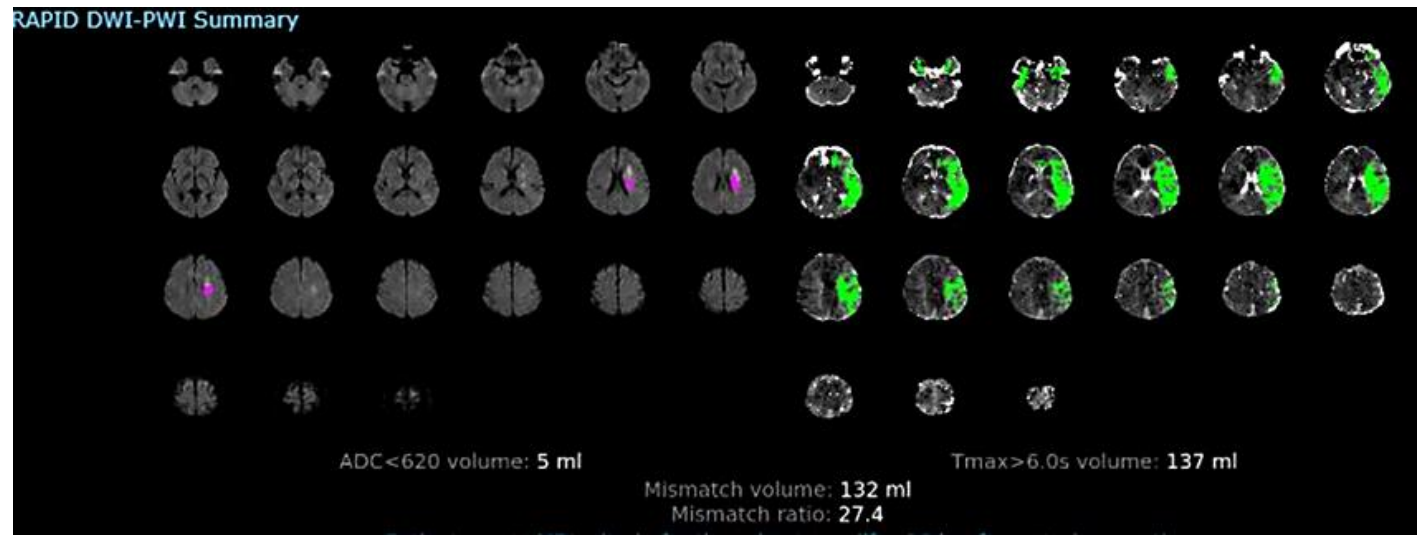

Fig. 3. Perfusion maps. The maps show unilateral perfusion deficits which correspond to patient's exam findings of right-sided deficits. The cerebral blood flow volume (less than $30 \%$ ) is $5 \mathrm{~mL}$ and the time to peak concentration ( $\mathrm{T}_{\mathrm{max}}$ ) more-than-6-s volume is $137 \mathrm{~mL}$; mismatch ratio 27.4 .

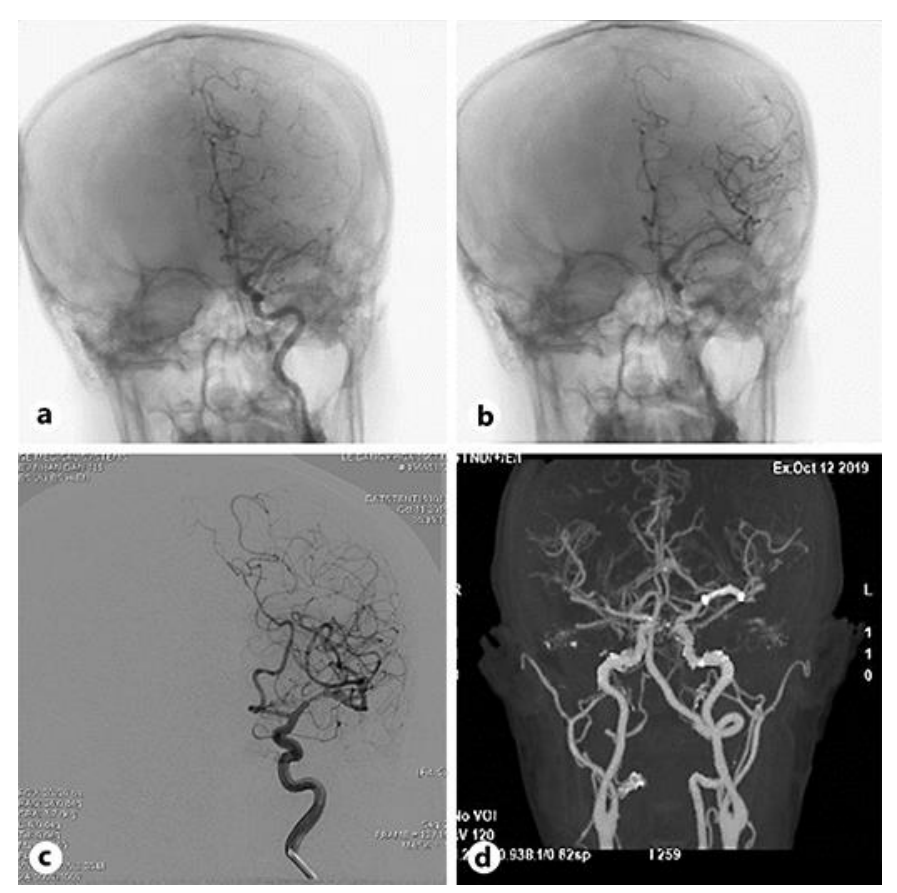

Fig. 4. a DSA revealed left M1 MCA occlusion. b Reperfusion after thrombectomy and angioplasty. c DSA after thrombectomy with severe stenosis left M1 MCA. d Angiography after stenting left MCA. 